\title{
LIGHTING: A DRIVER OF the sustainable revolution
}

\author{
Harry VERHAAR \\ Philips Lighting, The Netherlands \\ harry.verhaar@philips.com
}

Some of the most important things in life are taken for granted, and nowhere is this truer than with light. In this article, we will look at some important milestones marking light's path from human evolution to sustainable revolution, challenges facing the modern lighting industry as well as the world we live in, and what the future promises. In a sense, a new revolution is at hand. It would be hard to overestimate the fundamental importance of light as it shapes virtually everything we sense and experience.

publication of ADynamical Theory of the Electromagnetic Field, Scottish scientist James Clerk Maxwell demonstrated the wave properties of electrical and magnetic fields, and proposed that electricity, magnetism and light are different manifestations of the same wave-based phenomenon. As the wave light theory became generally accepted, Albert Einstein took a slightly different approach, describing in 1905 how light can also behave as particles, or photons. Through the centuries, many of our brightest scientific minds have worked to better understand the properties of light, and these discoveries have fueled the many technological advances to follow. larger class of optics. In 1865, with the

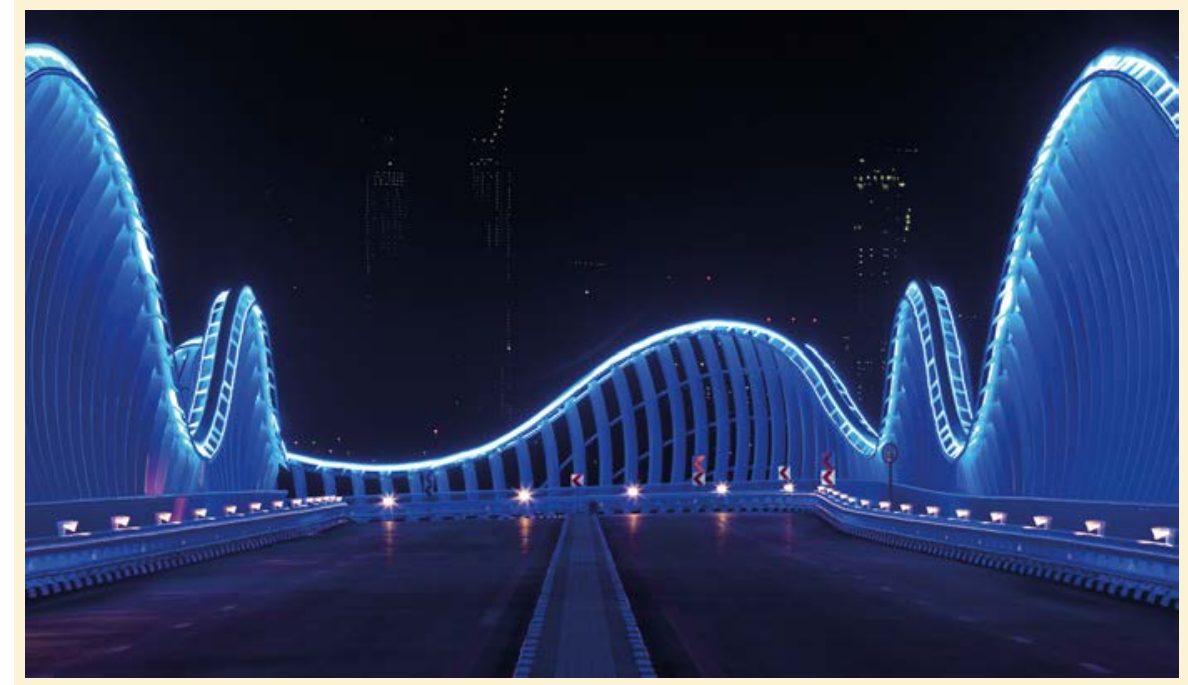

Meydan Bridge, Dubai.

\section{The first revolution: electric light in the home and workplace}

What can be considered the first revolution in lighting was the successful introduction, a little more than a century ago, of so-called "artificial" or electric light into the home and workspace. This leap forward was made possible by the convergence of two distinct technologies: widespread electrification and the invention of a long-lasting carbon filament lamp. Early carbon filament bulbs had a lifespan of 40 hours, while further refinements in filament composition increased lifespan dramatically. The first central power plant in the United States - became operational on September 4, 1882, serving an initial load of 400 lamps and 82 customers in a one-quarter square mile area. Only two years later, the station served more than 500 customers and powered more than 10000 lamps. The world's demand for more light and the power needed to generate it has grown exponentially in the years since.

In the quest for a more efficient technology, several families of gas discharge bulb were created including the fluorescent lamp. Fluorescent lighting came to be widely used in office and industry lighting applications because of its energy efficiency in relation to light output as compared to 
incandescent lamps. Compact fluorescent lamps (CFL) were later developed to replace incandescent lamps in the home. Additionally, high intensity discharge (HID) lamps, utilizing an electrical arc between tungsten electrodes mounted in a gas medium, built upon the earlier technology of the simple arc lamp to deliver more visible light per unit of electricity than either incandescent or fluorescent lamps before them. This family of lamp types is used primarily for outdoor applications such as the lighting of streets, stadiums, and retail locations.

Undoubtedly, the most promising technology to transform electric lighting in recent decades has been the development of the $L E D$, or light emitting diode, a format in which voltage is applied to a two-lead semiconductor triggering the release of energy - in this case illumination - in the form of photons. The lifespan and electrical efficiency of the LED lamp is several times greater than any of the technologies that have preceded it, offering tremendous benefits in terms of energy savings. In fact, the promise and potential of global adoption of LED lighting comes at a crucial point in human history.

\section{The challenges at hand}

When Thomas Edison threw the switch at Pearl Street Station in 1882, he directed about 600 kilowatts of electricity. Today, 7 billion citizens demand more than 20 trillion kilowatts. By 2050, with a population approaching 9.5 billion, demand could double. By that point, it is possible we could face a gap between energy supply and demand which some call the "zone of uncertainty". Beyond growth in population and energy demand, a variety of factors call for disruption in the lighting industry. One is increased urbanization: today $54 \%$ of the world population, 3.5 billion people, live in cities. By 2050 , it is projected that over two thirds, or close to an additional 3 billion, will be urban residents. Simultaneously, an additional 3 billion will become part of the middle class, increasing their energy use accordingly. By 2030 these global

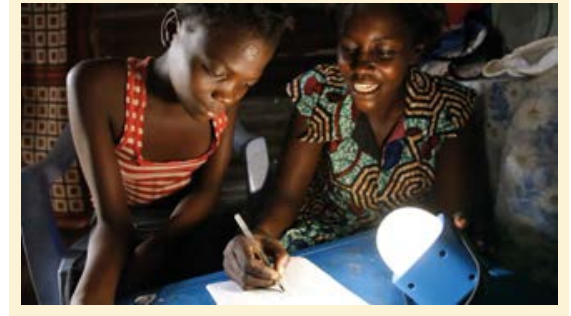

Solar-LED lighting enabling children to study and make their homework in the evening.

trends will already lead to an estimated $35 \%$ increase in the number of light points worldwide.

Underlying these already formidable challenges of growth, the realities of climate change force an urgent collective focus on reducing energy consumption and carbon emissions. Realizing the opportunity for the savings afforded by LED, on December 7, 2006, Philips took an unprecedented action in the lighting industry by calling for a global phaseout of incandescent light bulbs, the very basis and origin of the company. Governments around the world followed it. In 2009, the European Union initiated a phase-out of incandescent bulbs which was completed by 2012. In the subsequent years the lighting market transition has turned into a global LED lighting revolution.

\section{A second revolution: the promise of LED}

The promise of LED is profound, in part due to the alignment of two distinct technologies. Just as the incandescent lamp was integrated into the growing footprint of electrification more than a century ago, today the integration of connected LED technology into the Internet of Things means lighting need no longer be thought of as a matter of output but of outcomes. In the years ahead, continued advances in connected, user-centric lighting will transform the way we live, work, travel, relax, light our cities, grow our crops, heal the sick, and much more.

As a value proposition, even with the formidable growth in light points by 2030 , LED offers huge savings in terms of both cost of operations, and toll on the environment. In 2006 - the

\section{CAPABILITIES}

\section{YOUR PARTNER TO MEET YOUR UNIQUE NEED, \\ FICHOU OFFERS THE IDEAL KNOWLEDGE OF CUSTOM OPTIC MANUFACTURE ASSOCIATED WITH CUSTOM OPTICAL COATING DESIGN TO MEET YOUR NEEDS.}
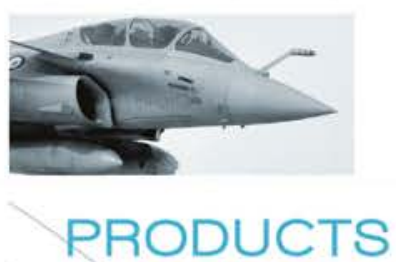

- CUBE , PRISM, MIRROR

- WAVEPLATE, POLARIZER

- LENS, BEAMSPLITTER,

- WINDOW, ...

- CRYSTAL, ROD, ...

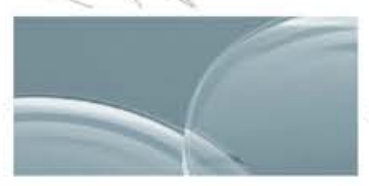

\section{COATINGS}

- ANTIREFLECTION COATING

- DIELECTRIC COATING

- METALLIC COATING

- infRARED coating

- CUSTOMIZED COATING

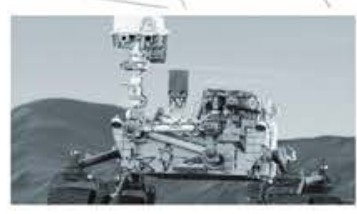

\section{CUSTOM REALIZATIONS}

- PYRAMID

- large sapphire window

- polarization optics

- polarization scrambler

- waveplate 150 mm diameter

- ACHROMATIC RETARDATION PLATE

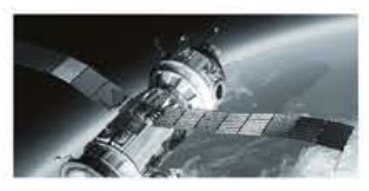

Certificated by AECMA EASE in accordance of EN9100 WWW.optique-fichou.com Fichou : 11 rue Louise Bourgeois, 94260 Fresnes FRANCE 

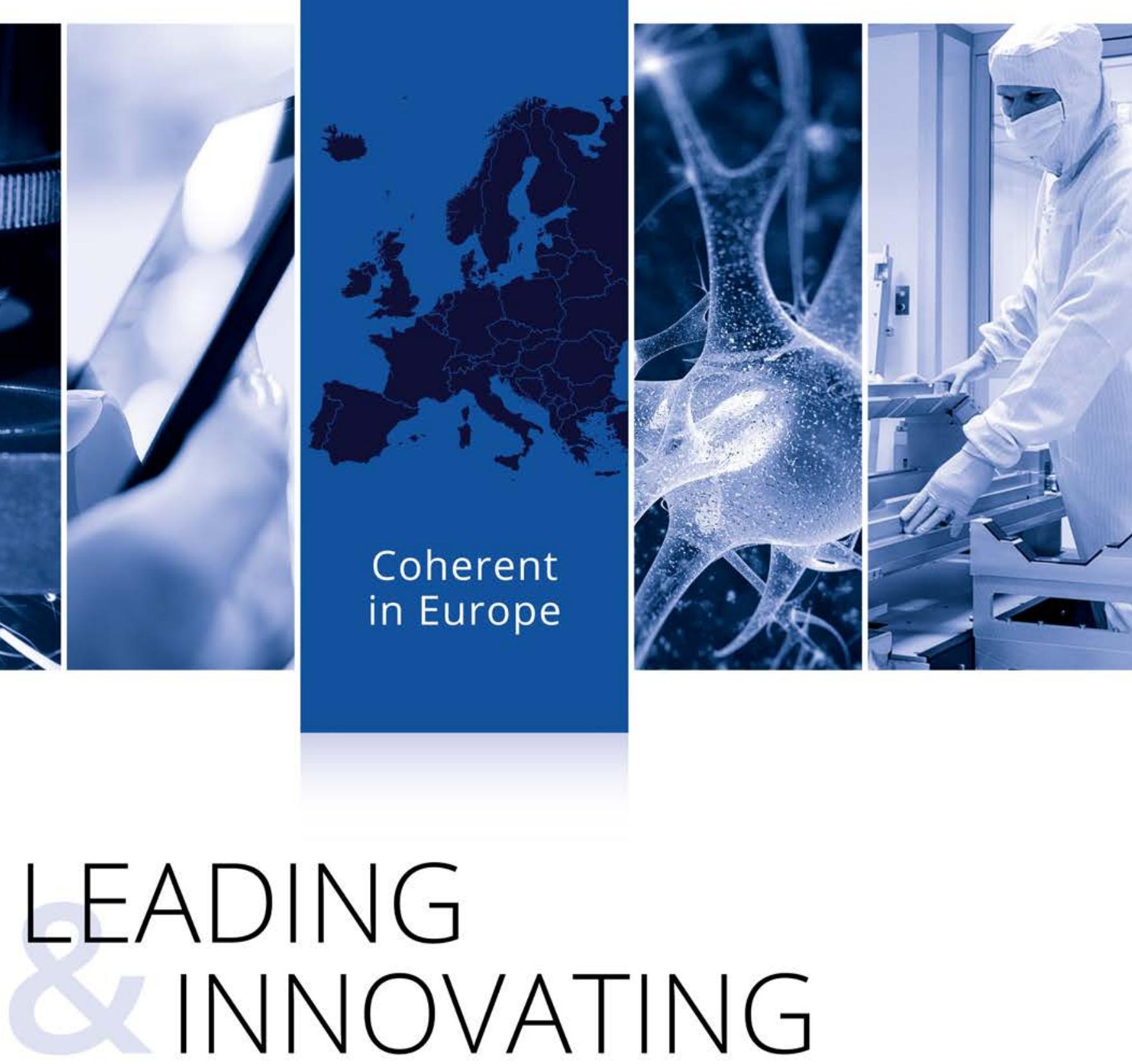

IN THE GLOBAL ECONOMY

Our multiple R\&D, manufacturing, sales and service locations in Europe deliver laser-based solutions of superior reliability and performance for a wide range of customers worldwide.

Materials Processing to Life Sciences, Microelectronics to Scientific Research Global Reach. Local Focus - coherent.com/excellence

\section{* COHERENT.




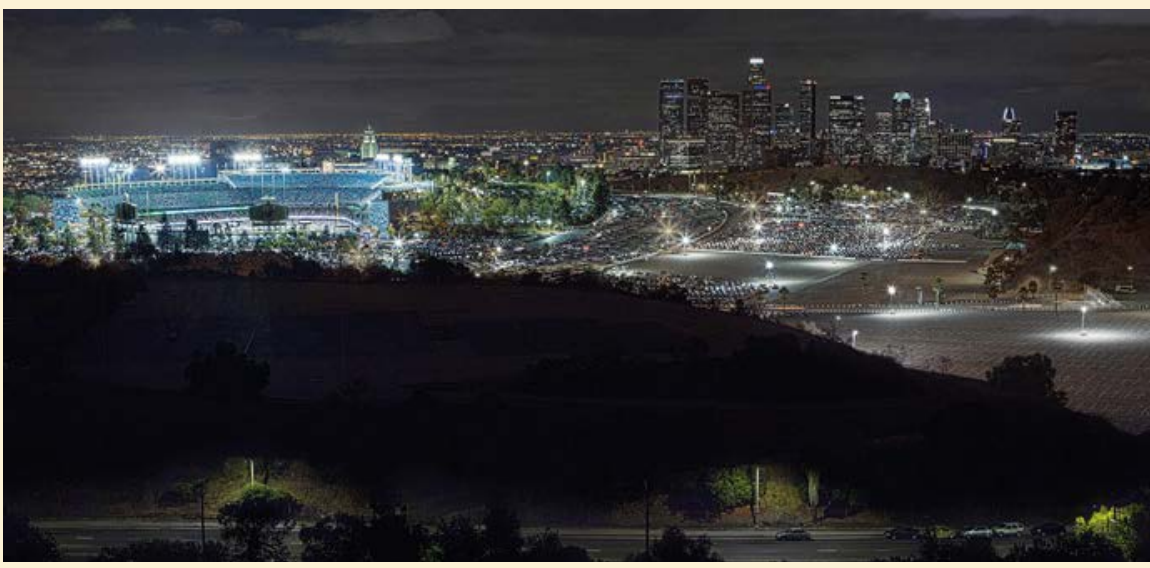

Citytouch connected LED lighting across the city of Los Angeles.

last year the lighting market was changing at an evolutionary pace - lighting accounted for $19 \%$ of global electricity consumption. A universal switch to LED lighting would reduce this proportion to around $8 \%$, curbing global carbon dioxide emissions by about 1400 megatons by 2030 .

Beyond energy efficiency, cost savings and reduced carbon emissions, LED offers tremendous benefits to our quality of life. LED can now be used in all applications, connected to lighting management systems and adjusted to produce new lighting experiences. The following examples highlight the advantages of positioning connected LED technology within the Internet of Things while giving an exciting glimpse of things to come.

\section{Connected cities}

The City of Los Angeles's public lighting system includes almost a quarter of a million streetlights - more than any other city in the U.S. Given that streets comprise fully $15 \%$ of the city's total area, it is no surprise that Los Angeles is known the world over as a driving city. But Mayor Eric Garcetti is determined to make Los Angeles a walking city as well. In 2015, he launched a Great Streets Initiative to revitalize neighborhoods by making the streets more pedestrian-friendly, and new street lighting technology that can ensure better and more reliable lighting operations was an important part of the plan.
In 2015, Los Angeles reported an energy saving of $63 \%$ and a cost reduction of almost $\$ 9$ million. The city offers a compelling model for the potential of connected street lights to deliver better, more energy efficient light.

\section{Connected offices}

The office space of the 21st century is rapidly evolving, and lighting plays a vital role in this transformation. A vivid example can be found in the Edge, an innovative, 40000 square meter, multi-tenant office building in the Zuidas business district in Amsterdam. Philips Lighting worked closely with OVG Real Estate, the building's designer, and Deloitte, it's primary tenant, to deliver a connected lighting system that enhances the flexibility of the open-plan office, where workers have no fixed desk, but rather utilize a variety of shared spaces from sitting desks, standing desks, meeting rooms or private enclosures. It is what the Dutch call het nienwe werken: the new way of working.

Beyond increasing comfort and productivity, the system also provides building managers with real-time data on operations and activities. Edge managers use the software to visualize and analyze this data, track energy consumption and streamline maintenance operations. This provides for maximum efficiency as well as a reduction of the building's $\mathrm{CO}_{2}$ footprint. The expected savings for the Edge are $€ 100000$ in energy costs and $€ 1.5$ million in space utilization costs per year.
Wavefront sensors and adaptive optics for optical metrology, lasers and microscopy
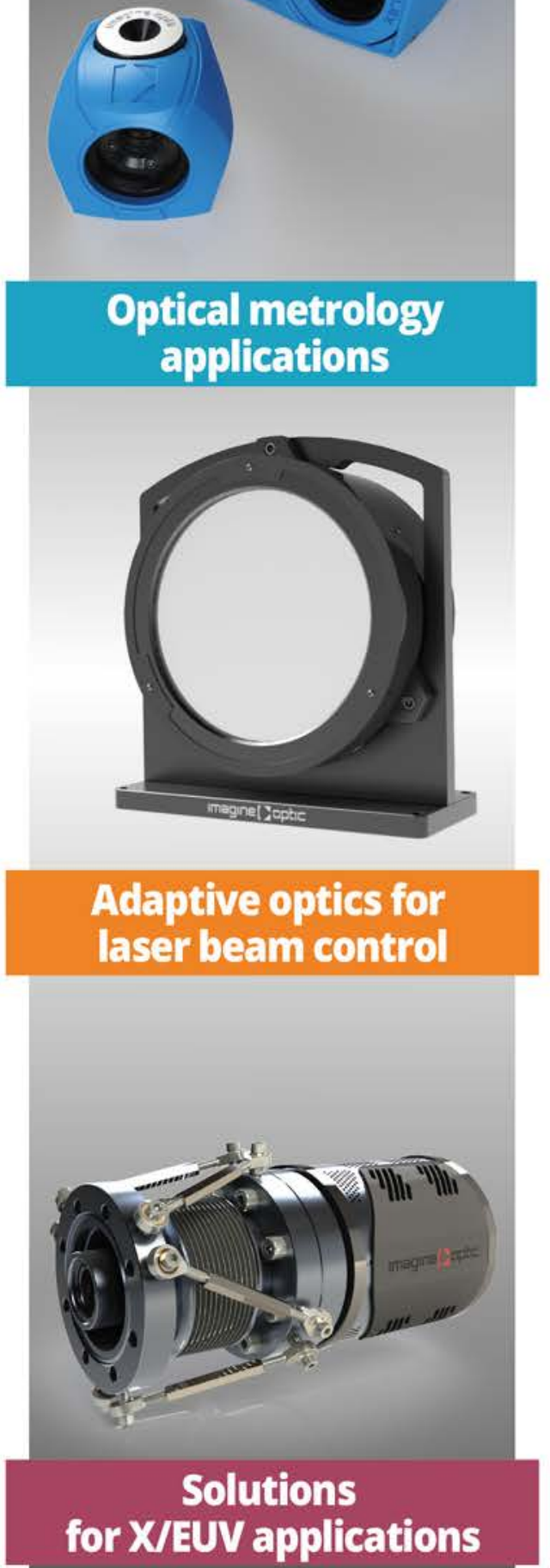

Contact us for more details: contact@imagine-optic.com or +33164861560 


\section{HORIBA}

Scientific

\section{TERS Proven!}

\section{NanoRaman ${ }^{\mathrm{TM}}$ : When Atomic Force Microscopy Integrates Optical Spectroscopy}

(6) Multi technique analysis platform from macro to nanoscale

(V) True Confocal Raman spectroscopy

(6) Robust, stable, ultimate resolution in AFM

(1) Multi-user friendly, short time to results

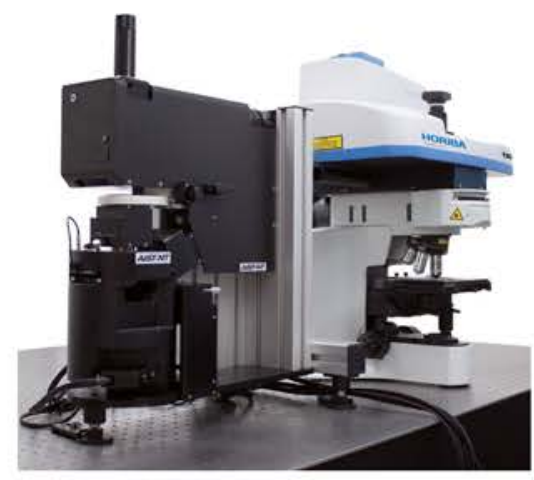




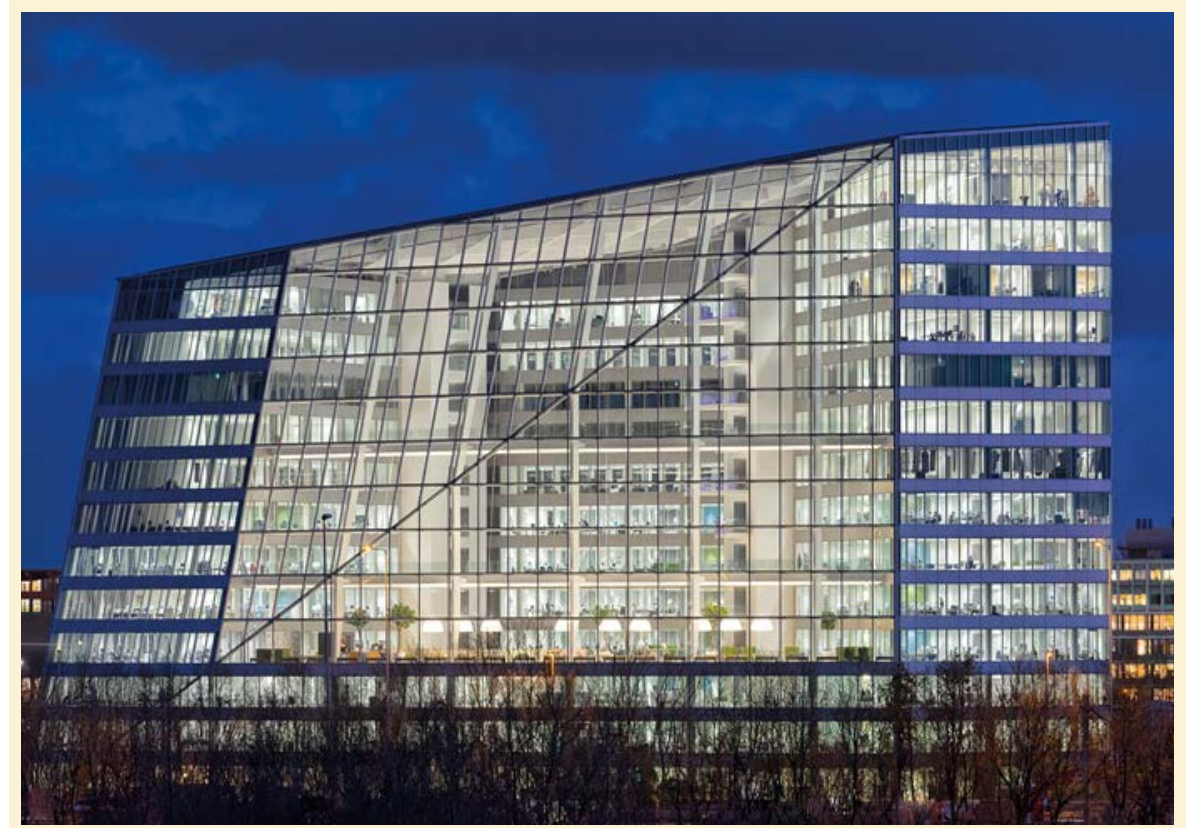

The Edge, Amsterdam, the greenest and most intelligent building in the world.

\section{Connected homes}

Lighting is one of the main interests in the Internet of Things for the home. Philips Hue was the world's first connected lighting system for the home when it launched in 2012, and has since become the system of choice for consumers.

Connected LED technology allows light to be an interactive part of the home environment. With more than 16 million colors to enhance any atmosphere, light recipes can be designed to help users feel more energized in the morning or more relaxed after a busy day.

\section{Eliminating light poverty}

As governments across the world look for ways to curb carbon emissions, improving energy efficiency is an urgent priority. In developing regions, solar lighting has given us huge opportunities to "leapfrog" outdated technology. Off-grid solar lighting is an important tool in driving down carbon emissions and accelerating global development. We don't have to wait for answers or new inventions. The technology we need is already transforming the lives of off-grid and urban communities in India.

\section{Something more} than illumination

From the capturing of fire as a tool, through technical advances that are transforming electric light into something more than illumination, lighting has undergone a dramatic evolution and seen equally dramatic periods of revolution. In fact, revolution is again in the air. In the years to come we will see the complete disappearance of the 19th century incandescent light bulb - the end of the first mass electrical appliance - to be replaced by 21 st century connected LED lighting systems and technology. Through ceaseless innovation and a commitment to the opportunities these breakthroughs afford, a new revolution is at hand: an era of more and better light - light that provides for a more sustainable world.

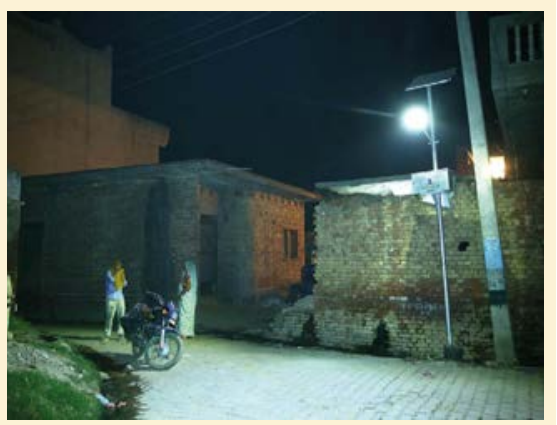

Uttar Pradesh, solar-LED streetlighting.

\section{YOUR PARTNER IN LASER \& OPTICS}
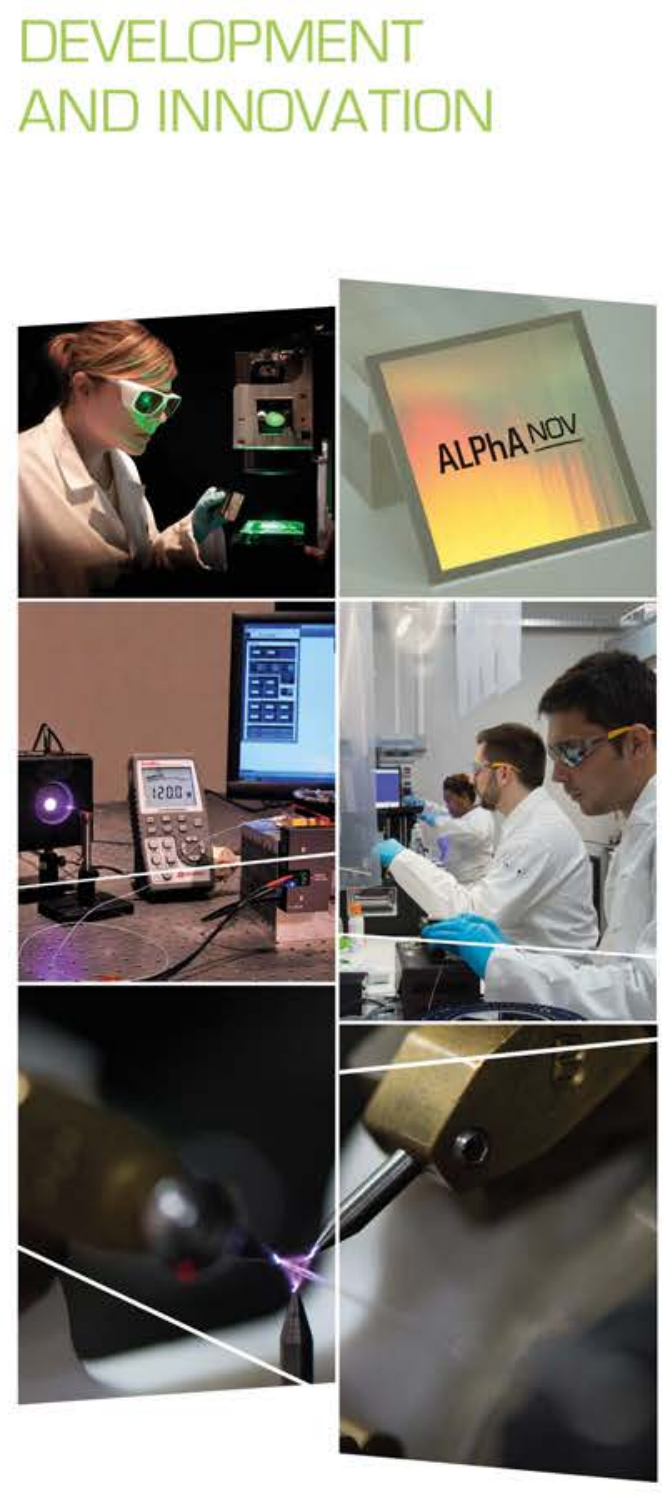

LASER PROCESSING \& MICRO-MACHINING LASER \& OPTICAL SYSTEMS LASER SOURCES \& FIBER COMPONENTS

$\square$ PHOTONICS FOR HEALTH PURPOSES 